Karin Dangermond*, Ricardo Weewer, Joachim Duyndam and Anja Machielse

\title{
"If it stops, then l'll start worrying." Humor as part of the fire service culture, specifically as part of coping with critical incidents
}

\author{
https://doi.org/10.1515/humor-2021-0106
}

Received May 3, 2021; accepted October 14, 2021; published online February 8, 2022

\begin{abstract}
Firefighters are reluctant to talk about firefighters' humor with outsiders. This closed attitude has led to a lack of understanding of this important coping strategy in the outside world. It is not clear how firefighters experience humor and its role as part of the fire service culture and why they consider humor to be important when coping with critical incidents. Data has been collected by means of 20 participant observations and 72 interviews with Dutch firefighters from 37 different fire stations. Joking culture and joviality are important elements of the Dutch fire service culture. Firefighter humor usually creates unity, but can also lead to exclusion. Whether a joke is perceived as funny depends on who makes the joke, the moment, the content, and the frequency of the joke. Black humor is used as a means to start a conversation and, indirectly, to make it possible to discuss emotions and it tends to positively influence group dynamics. However, black humor is absent in the case of certain critical incidents because of personal boundaries and unwritten rules. The absence of humor is a sign for the crew commander to pay extra attention to coping.
\end{abstract}

Keywords: critical incidents; fire service culture; firefighters; humor; informal peer support

\section{Introduction}

Humor is an important part of the culture of first responders (Charman 2013). It plays a role in building group cohesion (Greatbatch and Clark 2003) as well as

\footnotetext{
*Corresponding author: Karin Dangermond, Netherlands Institute for Public Safety, Arnhem, Netherlands; and University of Humanistic Studies, Utrecht, Netherlands, E-mail: karin.dangermond@nipv.nl. https://orcid.org/0000-0003-0973-8872

Ricardo Weewer, Netherlands Institute for Public Safety, Arnhem, Netherlands Joachim Duyndam and Anja Machielse, University of Humanistic Studies, Utrecht, Netherlands, E-mail: J.Duyndam@UvH.nl (J. Duyndam), A.Machielse@UvH.nl (A. Machielse)
} 
defining group boundaries (Kuipers 2009): only group members have the proper information (prior knowledge) to understand implicit references. Humor is likewise a coping strategy for first responders (Gross 2009), especially when confronted during their work with incidents that relate to personal loss and a threat to their well-being. These incidents, also known as critical incidents, often lead to critical incident stress (Fraess-Philips et al. 2017). Not all types of humor are equally effective in processing critical incidents though (Strick 2021). When coping with critical incidents, humor is described as black humor, also referred to as dark, gallows or cynical humor (Rowe and Regehr 2010). Black humor concerns sinister topics such as death, disease, injury, and disfigurement which are discussed humorously with the aim of expressing the absurdity, callousness, and cruelty of the world (Willinger et al. 2017).

Because of variations in requirements and tasks, first responders experience a different range of critical incidents under different circumstances - such as working conditions (e.g. length of shifts), the frequency with which they are confronted with critical incidents, and collaboration with colleagues. A proper evaluation of critical incidents and how first responders cope with them therefore requires separate studies for different professional groups (Halpern et al. 2009). This article focuses on firefighters with an operational function in the fire service in the Netherlands; it discusses the role of humor as part of the Dutch firefighting culture in general, and specifically when dealing with critical incidents.

How firefighters cope with their emotions is, to a certain extent, influenced by the fire service culture they experience (Haverkamp 2005). The culture present in the fire service organization affects firefighters' mental well-being and performance (Dangermond et al. 2021). Caused by its specific work that not only consists of fighting fires, but also rescuing people and animals, the fire service has a unique culture (Johnson et al. 2020) that is characterized by close cohesion and mutual trust (Varvel et al. 2007). Strong intra-group bonds are central to the functioning of firefighters (Johnson et al. 2020). A typical feature of the fire service culture is that it is an emotional culture, one in which the collective emotions of a group are key (O’Neill and Rothbard 2017). As part of this emotional culture, joviality - "markedly good-humored, especially as evidenced by jollity and conviviality” (O’Neill and Rothbard 2017, p. 81) - plays an important role in the assumptions, values, norms, rituals, artefacts and practices of firefighters. Humor is a significant part of the daily routines of the fire service culture (Thurnell-Read and Parker 2008). This is also partly a joking culture: "a set of humorous references that are known to members of the group to which members can refer and that serve as the basis of further interaction" (Fine and De Soucey 2005, p. 1). Firefighters rely on each other in dangerous situations, which is why they test each other at the fire station. Through humor, their mental weaknesses, 
physical strength, and resilience are exposed and, especially for career firefighters, humor is used to prevent boredom during (quiet) $24 \mathrm{~h}$ shifts (Ward and Winstanley 2006).

The culture of firefighters may influence the impact of critical incidents, for example because of group expectations and standards applying to critical incidents (Jeannette and Scoboria 2008). In stressful and often life-threatening situations, and when coping with these situations, firefighters use humor to express their feelings, to ensure social support by developing group cohesion, and to distance themselves from the situation to enable effective action (Rowe and Regehr 2010). In brief, firefighters describe humor as an important coping strategy for dealing with stress and complex situations (Haslam and Mallon 2003).

Although humor plays an essential role in how firefighters perform their work (Rowe and Regehr 2010), it is not clear how they experience the role of humor as part of the fire service culture and why they consider it to be important or unimportant when coping with critical incidents. Firefighters' use of humor, specifically black humor, is not always understood or accepted by outsiders (Moran and Roth 2013), and is considered "politically incorrect" and "unacceptable" (Goble 2020, p. 18). This has made firefighters reluctant when it comes to sharing information about the use of humor, which may be the reason why relatively few studies into this subject are available. Plus, firefighters are an under-researched group in academic literature anyway (Fraess-Philips et al. 2017).

More in-depth knowledge and a better understanding of the role and function of humor, including black humor, within the fire service is important in order to customize assistance and aftercare more accurately to the needs of firefighters. Hence, the question investigated in this article is: What role does humor play as part of the fire service culture in general and specifically when dealing with critical incidents?

\section{Research method}

The study in this article is part of research in the Netherlands into the role of fire service culture in coping with critical incidents. An ethnographic field study of a highly exploratory nature was conducted in order to answer the main research question. The principle underlying ethnographic research is that groups of people, such as firefighters, live together for a certain period of time and develop their own cultures (Patton 2015). Long-term participation in the world of firefighters - to build trust and to talk about their personal experiences and perceptions - is conducive to achieving a better understanding of the role of humor in coping with critical incidents and the interactions between firefighters and their group culture. 
This makes the present study a good complement to previous research into humor in fire service organizations (Fine and De Soucey 2005; Moran and Roth 2013; O’Neill and Rothbard 2017; Rowe and Regehr 2010; Sliter et al. 2013; Yoder and Aniakudo 1996).

An ethnographic field study is also the most appropriate design for the current study, as it focuses on a sensitive topic that may be considered taboo by those involved. Various studies have described how a cultural stigma hinder firefighters from discussing mental health issues (Gulliver et al. 2019; Henderson et al. 2016; Stanley et al. 2017; Tamrakar et al. 2020). Their use of firefighters' humor or black humor is not always understood or accepted by outsiders (Moran and Roth 2013). Firefighters are reluctant and unable to provide information and engage in intensive interaction with researchers unless they trust the researcher. An ethnographic field study offers more opportunities to discuss matters in confidence. An important fact in this study is that the first author works as a researcher at the Dutch Fire Service Academy, plus, belongs to a fire service family. She therefore can be seen as an insider researcher (Green 2014). Such researchers are more likely to be accepted by the population being studied and have relevant prior knowledge at their disposal, which makes it easier to ask more in-depth questions (Kniffin et al. 2015). However, insider researchers may encounter interviewer bias and ethical and moral dilemmas (Floyd and Arthur 2012), for example because of personal or professional relationships with participants (Perryman 2011; Vass 2017). In this study, many participants indicated that they considered the researcher to be "part of the family."

\subsection{Data collection}

The visible part of the fire service culture, open behavior, was described during participant observations. A total of 20 participant observations took place in six crews of career (professional) firefighters from six fire brigades. The researcher was present throughout several $24 \mathrm{~h}$ shifts per crew and participated in all activities (with the exception of providing aid during incidents). In addition, observations were made during evening drills (with non-career (volunteer) firefighters). Observation reports were made during and immediately after each participant observation. In addition to listing some factual characteristics, these reports mainly contain descriptions of the atmosphere, the incidents (if any), special moments, crew commanders' roles, group dynamics, and informal aftercare.

To deepen this descriptive behavioral level and to actually understand the culture, individuals' patterns of perceptions, thoughts, feelings, and experiences have also been studied by means of individual interviews (Schein 1984). A total of 
72 semi-structured in-depth interviews were held; participants were selected by means of theoretical sampling (Patton 2015), a targeted selection based on considerations from the literature (e.g. firefighters with many or actually few years in the fire service, career and non-career firefighters). The list of topics for the interviews was based on participant observations and relevant literature. The main themes in the list of topics are: a description of the fire station and the fire crew, sense of community, the crew commanders' roles, critical incidents, social support, and the role of humor. Participant observations as well as semi-structured indepth interviews were conducted in each crew of career firefighters selected. This enabled observation results to be compared with the results from the semistructured interviews (and vice versa), in order to supplement or correct them or add more in-depth details. The face-to-face in-depth interviews took place in fire stations, in public places, or at participants' homes. Each interview took one-anda-half to $2 \mathrm{~h}$. All the interviews were taped on voice recorders and transcribed verbatim. All participants signed an informed consent statement in advance.

\subsection{Sample}

The Dutch fire service is made up of 23,570 firefighters (4,357 career firefighters and 19,646 non-career firefighters) and 969 fire stations (Netherlands Institute for Safety 2020). The study population comprised crew members, crew commanders and shift leaders: 40 career firefighters, 20 non-career firefighters, and 12 participants who were both career and non-career firefighters were involved - 5 women and 67 men, with an average age of 43 and an average length of service of 19 years. The participants represented 19 professional and 18 volunteer fire brigades.

\subsection{Analysis}

The analysis was an iterative process alternating data collection, analysis, and theory formation processes. Induction and deduction took place simultaneously. The Atlas.ti qualitative analysis program was used to analyze the data. Three coding steps were applied: open, axial and selective coding (Patton 2015). Open coding was mainly applied when analyzing the interviews and participant observations (e.g. the codes: "fire service culture humor," "group dynamic," and "formal/informal processing”). The data was axially coded in the next step. As part of this step, codes were validated by splitting, merging, and comparing codes, and identifying new codes (e.g. splitting the code "fire service culture humor" into the subcodes "humor-processing incidents," "humor-creating atmosphere" and 
"humor changed over time"). In addition, several codes were clustered into one or more group codes, based on detailed considerations (e.g. "stimulating" and "barriers" of humor in processing critical incidents). Lastly, individual and group codes were compared in order to analyze their correlation. Data was collected until the first signs of saturation appeared.

The triangulation of methods added depth to the study results. The different forms of data collection enabled us to study the participants from different perspectives. Observations were conducted to chart what could be observed externally, interviews served to gather more in-depth knowledge. The combination of the prolonged participant observations, the many semi-structured in-depth interviews and the detailed, structured methods used to collect and analyze data enhanced the validity and reliability of the research and optimized the trustworthiness of the data. In all steps, the first author worked closely with an expert on the subject (second author) and two academic non-insiders (third and fourth authors) (researchers' triangulation) - from critically reading transcripts of the interviews to reviewing the codebook.

\section{Results}

The findings are clustered in themes and supported by quotes from the interviews. Quotes have been altered for editorial reasons and to safeguard the anonymity of participants.

\subsection{Humor as part of the fire service culture}

We first discuss how participants explain the role of humor as part of the fire service culture. The various types of humor and the times and occasions when humor is used were identified next. Lastly, we addressed humor that discriminates against certain people and excludes them.

\subsubsection{The importance of humor as part of the fire service culture}

Humor plays an important part in the fire service culture for several reasons. It is not only the joke itself that matters, but also the person who makes the joke (the joker), the person who is the subject of the joke and their reaction (the target), and the person(s) who are present during the joke (the audience).

Participants mentioned various reasons why they thought humor played an important role as part of the fire service culture and which functions humor serves. 
Firstly, humor produces a good atmosphere in the crew. A good balance and variation between serious firefighting and rescue activities on the one hand and light-hearted informal conversations on the other are valued. "Me saving someone doesn't concern me personally, it's my job. But the laughter here, that makes me feel happy" [R.57]. Secondly, it was indicated that, in the fire service, humor is seen as a means of communication. Jokes are used to indirectly convey a message: "Often in the form of a joke, but always with a kernel of truth" [R.17]. Using humor in this way enables the informal hierarchy (positions) in a crew or brigade to be influenced. An example of this humor is jokes about mistakes people have made. “Like, 'hey, you couldn't do it, could you?' It is stated as a joke, but in this way the others will find out and you'll descend to a lower position in the pecking order. That's their intention" [R.9]. This may be due to conflict avoidance (because the paradigm states that conflicts do not belong in a well-functioning team), yet participants find it difficult to explain why they communicate their message in the form of a joke. "So that you won't have to comment on it directly. Ignorance as to how to communicate it differently I think, or maybe not wanting to start the conversation, being afraid of the other person's response. Maybe” [R.96]. Thirdly, humor is used in order to test each other: "Teasing each other in a fun way; it keeps us all alert, you get to know each other, it's about resilience and endurance. You know if you can rely on each other" [R.98]. Fourthly, humor relates to self-mockery: deliberately making jokes about oneself. For example, because someone doesn't want to be the target of someone else's joke, like this participant: "If I beat them to it, they'll be done. I make the joke myself, so that they can't do it anymore. They won't get the laughs because you were ahead of them" [R.21]. A lack of acceptance by the group also plays a role in self-mockery: "He's not accepted and he senses that too. He's always joking about it, so that others will not make those jokes" [R.96]. The fifth and final reason given is that black humor plays an important role in coping with critical incidents. This subject is further elaborated on in the next section.

Almost all participants have a colleague in their crew who takes the initiative to make jokes, "a first-class clown" [R.94]. An important condition for the acceptance of humor is that the joker is from one's own crew or brigade. It was often mentioned how jokers carefully considered who to tell the joke to and the possible reactions this might produce. "I pay attention to who's in the group. With some of them you factor in that what goes around comes around" [R.19]. And people in leadership positions are faced by a dilemma: should they joke, given their positions?

Almost all participants have been the target of a joke at one time or another. According to participants who feel that humor is an integral part of the fire service 
culture, it is an unwritten rule that colleagues are expected to be able to take a joke. Humor is often considered to be a selection criterion (test). "That's the culture in the fire service. Jokes will be made. Sometimes you're the laughingstock and the next time someone else is, and you just grin and bear it. Otherwise, I think you should go find another job" [R.61]. Participants indicated it is important that people handle this in a light-hearted way. A 'suitable' reaction is "to just go along with the joke" [R.51]. Someone who does not react appropriately will soon be the target again. "They do have a radar for that. If you don't handle jokes well, they're bound to make them" [R.23]. The importance of reciprocity was also mentioned several times in this context: "If I don't want to be the subject of a joke, I shouldn't make any myself. That's why I don't experience this as negative or annoying” [R.83]. There are extenuating circumstances that keep someone out of jokes way temporarily, especially if they are having problems at home. "One member of our crew is going through a divorce. He's really having a hard time, and has told the crew so. We keep it in mind. No bad jokes about this. Well, maybe a bit" [R.56]. Several participants said that being the target of a joke, if within proportions, was considered to be proof of being a fully-fledged member of the group. Never being the subject of a joke is actually perceived to be a problem. "Not having the mickey taken out of you is worse than if they're taking the mickey out of you, because the mickey-taking actually means they have a certain bond with you" [R.94].

\subsubsection{Humor in the fire service: differences and similarities}

Participants indicated that the extent and type of humor differs per crew or per brigade: it depends on the group composition as crew members copy and influence each other's behavior. "We encourage each other. One person makes a comment, the next person will take it a step further and so on. Things can get pretty lively then" [R.9]. One moment this becomes visible is when people switch crews. The dynamics can also change when new colleagues, who people have been joking about, join the crew or the brigade, for instance, female colleagues or colleagues from other ethnic backgrounds. Participants also indicated that humor has a common denominator and is quite similar all over the country. As a participant from the Hague explained: "When I come to Amsterdam, I hear the same jokes within fifteen minutes. About the schedule, the B crew making jokes about the $\mathrm{A}$ crew, the $\mathrm{C}$ crew about the $\mathrm{B}$ crew. There is no way you can put an end to this. If it stops, then I'll start worrying. It's what we have in common. It's a cultural thing” [R.2]. 


\subsubsection{Humor during collective moments at the fire station or digitally}

Humor occurs at or around the fire station during collective moments such as a $24 \mathrm{~h}$ shift, an evening drill, special occasions such as a colleague's retirement or anniversary, and after a deployment (further elaborated in the next section). Many jokes that had been made following a preconceived plan were described during the individual interviews. The participatory observations made clear that also other, more subtle or more ad rem jokes are made as well, such as puns, one-liners and insider jokes.

Participants mentioned several moments when jokes were played on each other at the fire station. For example, during dinner: "Baking coffee filters into pancakes" [R.72]; while sleeping: "The bedrooms were one floor up, I was tired so I went upstairs. I opened my door and saw that my bed was gone. I found my motor bike in my room. So, I took for a spin, and drove it downstairs" [R.58]; during drills: "Good fun, joking and goofing around a bit, and then it's time for serious business" [R.43]; and on special occasions, such as celebrating an anniversary or when leaving the crew.

Jokes are also shared digitally, particularly via WhatsApp groups. In formal WhatsApp groups fire service related issues are discussed, but in the informal groups unofficial information is shared casually: "A lot of nonsense, jokes, pictures, video clips, sometimes quite obscene” [R.21]. Several participants had left the informal WhatsApp groups because they did not like the information that was being shared: "Some messages were quite filthy and that's not my cup of tea" [R.61].

Several participants indicated that humor had changed in recent years, specifically physical humor. Where, in the past, objects or inventory might be sacrificed for the sake of a joke, today that doesn't happen very often anymore. Participants attribute this to three reasons: 1. the arrival of mobile phones: "In the past there use to be a lot more making each other wet and throwing water, that's all become less, long live the mobile phone" [R.40]; 2. the fact that the old generation has left and a new generation has come in: "These traditions are gradually becoming less, people find it less important" [R.67]; and finally 3. because old, outdated fire stations are replaced by new fire stations and people are careful to keep them in mint condition: "I remember occasions when there was pudding all over the station walls, but this new station is difficult to clean” [R.71].

\subsubsection{The downside of humor: exclusion and discrimination}

Participants identified a negative side to humor. Some indicated that some jokes are perceived as hurtful. There are various reasons for this. Whether a joke is 
perceived as such depends on the actual moment, the content (especially if jokes are perceived as a mechanism for exclusion and discrimination), who makes the joke, and the frequency of the joke.

Not everyone in the crew or the brigade feels like humor at the same time, although there are certain expectations (unwritten rules) about how someone will react. "On the one hand it's all great fun and on the other hand it can be hard at times, if you're not in the mood" [R.50]. It was indicated that the dividing line between humor and being bullied can be very thin. "We can see something as humor, which is actually not that funny at all. And definitely not for the person whom it concerns. If they react in a way that the crew likes, it's still thought to be funny. And sometimes you decide not to show your true feelings, because things will even get worse then" [R.57]. Some participants mentioned examples of jokes that discriminated against them because they were 'different,' especially gays and lesbians, women and firefighters with an immigrant background. "I'm under a magnifying glass, women feel that problem as well. We have to do more to prove ourselves" [R.9]. One participant recounted that someone jokingly asked whether pink cakes should be ordered because the participant in question was gay. Other brigades started calling his brigade the "gay brigade." "Those kinds of clichés. I think it's inherent in groups. Of course, they do it behind your back. It doesn't bother me personally, but in itself it is a problem, since it prevents other firefighters from being themselves" [R.19]. The use of clichés in the form of a joke was frequently mentioned, as was their trivialization. "Discrimination, but then in the form of a joke. It's less bad now. It used to be quite severe. The only thing you could do was grin and bear it. And then there's the denial. They don't see it, or they don't want to see it. But that's true for discrimination in general. I had to swallow a lot. And get angry. And wonder; don't they get it?” [R.9].

Most participants who experience discrimination in the form of jokes confront the joker(s) with their experience. However, it does make a difference here who the joker is, if it is someone from their own crew or someone outside the crew. "It depends on who's said it. You know each other, you sometimes joke and I know what I'm like and they know what I'm like. But it's something else if someone you don't know well makes such a joke. Who are you to judge me like that?" [R.58]. Some participants deliberately opt not to react, "I have become quite hardened over time and that's taught me that the wise thing to do is to keep my mouth shut" [R.55]. Confronting colleagues is not only the group's responsibility, it's also specifically the crew commanders' responsibility. To quote a crew commander: "Discrimination is a difficult issue. We've discussed it, everyone should feel at home. Joking is OK, but this shouldn't be the norm. It's still quite tricky. Some people get it; others say 'don't be a killjoy, it's just a joke'” [R.20]. 
And lastly, it was indicated that it's not only the content of a joke which can go too far, but also the frequency with which a joke is made, or both - a crew commander said: "I thought that conduct toward a certain colleague was improper. A certain kind of humor which I thought was going too far. The occasional joke is okay, but it has to stop at some point. The limit had been reached and I got them all together to discuss it” [R.12].

\subsection{Black humor when coping with critical incidents}

For most participants, humor plays an important part in coping with critical incidents. Participants refer to "black humor" in these cases, to distinguish it from the other (previously described) roles of humor. The section below explains what participants consider to be black humor and why they believe that this humor helps them to individually and collectively cope with critical incidents. The role that rituals play in here is presented next. The boundaries of black humor are subsequently discussed and it is explained why, according to firefighters, black humor is not intended for outsiders.

\subsubsection{Examples of black humor}

Some participants described humor when coping with critical incidents as "black humor, also sarcastic, gallows humor” [R.17]. Some jokes refer to the circumstances of an incident: "A resuscitation in a sushi restaurant, all you can eat. The gentleman didn't make it. On our way back one of our colleagues said: 'Well, that was all he could eat.' We couldn't stop laughing. It sure did take the tension away" [R.51]. Others mentioned black humor in connection with the specific physical situation of a casualty: "Someone had lost his foot in a serious accident. He was walking through a field. Then someone said 'well, he can always help the farmer plant potatoes, he'll be great at making the planting holes.' Rather black humor actually" [R.52].

\subsubsection{Using and listening to black humor: the individual (joker) and the collective (audience)}

Black humor is used in order to individually and collectively try to reduce the impact of a critical incident that has been experienced. Participants state that this type of humor is used as a means to start a conversation and to indirectly enable emotions to be discussed. Joking with other crew members while coping with such incidents generally has a positive influence on group dynamics. To them, additional 
information (for example "what happened, who did what and who didn't” [R.65]) is required after certain critical incidents before there is room for black humor as part of the coping process.

Almost all participants used black humor to cope with a critical incident; this type of humor is considered to be "crucial" [R.67] to the coping process. "Highly macabre jokes, that is how we cope" [R.2]. Joking usually starts immediately after an incident is over, upon leaving the scene of the incident: "to get rid of the tension, let off steam" [R.22], "to make things less intense, to put yourself in a rather more lighthearted mood" [R.67], "because it takes the edge off things a bit, it has a healing effect" [R.72], "it creates an opening for a discussion and everyone can share their thoughts" [R.50], "a sort of burden is lifted off you then, you shake it off and carry on" [R.62] and "it helps you put things in perspective, it becomes less heavy" [R.52]. Humor was often identified as an instrument to start a conversation: "humor is a good way to engage people. In a way, it lets others see that it's on your mind as well. It's an unintentional way of sharing that things gets to you as well” [R.3]. It breaks the silence, “altering people's mind set a bit” [R.26]. These quotes are examples of approach motives (goal-oriented behavior). Examples of avoidance motives (constrained goal-oriented behavior) are also mentioned, albeit to a lesser extent for example: "humor distracts from what just happened" [R.65]. Humor can also be used because participants cannot or do not want to directly share their emotions after a critical incident, "If you add a humorous touch to it, you do manage to say things that could not to be discussed otherwise. You go through some very intense moments" [R.22]. Another reason is that colleagues do not always recognize and/or accept emotions. A joke can be a safe way to discuss an incident and its impact. "In our macho environment, you're not easily inclined to exclaim 'I find this scary or I don't like it.' People will then make fun of you. That's not what you want. So you make a joke or you change the subject to other incidents" [R.7].

Besides making jokes, listening to direct colleagues' jokes can also help when coping with an incident. It was indicated that the jokes that are shared among the crew tend to positively influence the group atmosphere. Humor creates unity among the crew, "It puts you back on the same wavelength. You can connect with each other again. We've been through something, it's open for discussion and we can laugh about it. That's what humor does, especially among the crew. It brings unity" [R.50]. This is also true if it has been a longer time since the incident, when sharing memories of past incidents with each other.

\subsubsection{Rituals after a critical incident}

Participants stated that they also used humor as a kind of ritual after a critical incident. This mainly concerned "first-time" incidents for colleagues, and the 
rituals very often involve or have some reference to food. For example, buying ice cream: "We had colleagues buy us a treat to commemorate their first fatality. Stop by at the ice cream shop, two scoops with whipped cream" [R.1]; or a bakery: "The first time is usually pastry. There's this one colleague who kept bringing cake every week. It was just a joke, but he thought we were serious” [R.51]. Jokes about dinner (such as spaghetti, steak tartare or spareribs), as a reference to the incident: "If you just had a casualty, there'll be spareribs for dinner. This is actually quite weird, but that's coping" [R.4].

\subsubsection{The boundaries of black humor}

Participants stated that with certain critical incidents no black humor comes into play, as people instinctively refrain from crossing certain boundaries. In such situations, humor is perceived as inappropriate. "It's always inappropriate, but that is really inappropriate. When it's painfully quiet in the back, you do have something to talk about afterwards" [R.72]. Participants found it hard to explain why they actually refrain from joking about certain critical incidents. "If you think about it, I wonder what's the reason? It must be a sort of unwritten rule. Or just a feeling that everyone shares" [R.84]. This holds specifically true for critical incidents involving children and young adults - it isn't only children who are victims, but their parents too. "This is so bad, you can't joke about it. The severity, the impact, not only for yourself but definitely also for the parents. You can imagine or sense what that must be like" [R.98]. And finally, the absence of humor has to do with the feeling of helplessness while rendering assistance. "Incidents can make you feel rather helpless. I haven't been able to do anything. None of us have been able to do anything, although we came here to rescue someone. You feel defeated then" [R.62].

A joke's timing plays a role in the context of coping. Although black humor often starts immediately after a critical incident, there are also critical incidents where no jokes are made until after the first debriefing or evaluation has taken place and it is clear how the emergency response devolved. "When all of you together fill in the picture, then the joking and goofing around starts, simply because it helps you cope" [R.62]. However, this timing is not the same for everyone. This is because black humor is not always helpful in coping with critical events at the same time for everyone on the crew. It depends on people's personal needs. Several participants (especially crew commanders) indicated that if colleagues do not laugh about the jokes, it is a sign for them that coping should be given some extra attention. "You can see it in their faces, if someone doesn't share in the laughter. It can be hard to identify this, because you want to cope with the 
incident in a light-hearted way as well. But you should realize that some people may handle it differently" [R.96].

\subsubsection{Fire service humor and black humor are not intended for outsiders}

Generally, participants find it hard to discuss the role of humor as part of the fire service culture and as part of coping with critical incidents with outsiders. They think that outsiders do not understand this. "We have a lot of humor but outsiders don't find it as funny as we do" [R.42]. Outsiders are not only non-firefighters (civilians), but sometimes also other firefighters from outside the crew or the fire brigade. They don't always get the inside jokes, nor are they expected to. "Crews have their own jokes that others don't understand at all. They are often in-jokes that you don't get until you've been part of the crew for some time” [R.72]. A substitute from another crew mentioned: "Making sarcastic jokes in your own crew is fine, because you know each other. But you don't do it there, with the other crew. People will then wonder what you're doing” [R.78].

Some participants also indicated that black humor after a major incident is not intended for people outside the fire service. "A decent person might think 'that's antisocial, why don't you behave normally.' But it is effective. You cannot label or identify it in advance either. It just happens. What's good and what's bad?” [R.17]. Although it was indicated that the use of humor is effective, it was also emphasized that humor is not intended to be disrespectful to potential casualties even though it might come across as such. "There are times when a joke might come across as being awfully disrespectful, to the casualty, to an outsider. I can definitely imagine that" [R.72]. This is why some feel that their humor should not be shared outside their crew or brigade. "Venting jokes in the vehicle, preferably with the windows closed, so no one can hear" [R.49].

\section{Discussion}

Firefighters are generally reluctant to talk about firefighters' humor with people outside their own firefighting crew or brigade. This study has shown why firefighters think humor plays an important role as part of the fire service culture in general and specifically when coping with critical incidents.

In line with previous studies (Fine and De Soucey 2005; O’Neill and Rothbard 2017), the results show that a joking culture and joviality are important elements of the Dutch fire service culture. Firefighters in our study indicated that humor creates a good atmosphere. It is considered to be a means of communication, a way to test each other, and humor in the form of self-mockery is used as a defense mechanism. 
Lastly, humor is used in order to jointly cope with critical incidents. There are expectations about who the joker will be (someone from or outside the crew), who the joke will be about (the target), and how that person will react. In brief: jokes are made in a context in which unwritten rules play an important role.

Fire service humor plays a role in building group cohesion and defining group boundaries; these findings are consistent with previous research (Greatbatch and Clark 2003; Kuipers 2009). Although the results of this study describe how humor typically creates unity within the fire service crew or brigade, firefighters also noted the downside of humor. Several firefighters felt excluded as a consequence of humor in various ways. Firstly, and in line with other studies (Yoder and Aniakudo 1996), humor (in the form of pranks) is used as a mechanism to exclude fellow firefighters who do not conform to the dominant norm at the brigade (such as gays, lesbians, women and firefighters with an immigrant background). Secondly, it appears that firefighters who are never the target of a joke do not feel part of the group. Thirdly, this is the first study to point out that there are different circumstances due to which some firefighters - contrary to a majority of their crew - do not always perceive humor as funny and thus are (or feel) excluded from the crew. This is particularly true if they fail to sufficiently recognize implicit references; the dominant group dynamics exceed one's personal boundaries with respect to making a joke and/or joining in the laughter; the target of a joke cannot laugh about it because of the timing, content and/or frequency of the joke; and humor in the form of self-mockery is used as a defense mechanism. Since firefighters do not always distance themselves from the group or respond in a socially desirable way if they are able to, humor that crosses boundaries is not always identified as such. Hence humor can bring unity to a crew yet can also divide crew members.

Black humor (e.g. in the form of puns and rituals) is a strategy that plays a crucial role when coping with critical incidents. Firefighters have experienced that black humor reduces the impact of negative experiences. Black humor is used as a safe way to express feelings and to obtain social support. It also enables firefighters to distance themselves from a situation (Rowe and Regehr 2010). Firefighters have approach and avoidance motives for using humor, primarily for reasons related to coping with an incident. It is unclear whether they use black humor because it enables them to operate more effectively (Rowe and Regehr 2010). Lastly, not only making jokes oneself but listening to immediate colleagues' jokes also helped people cope, mainly because this positively influences the group atmosphere and creates unity. This is an important finding, as previous studies show that informal peer support reduces the impact of critical incidents (Varvel et al. 2007).

The study reveals that a joke's timing is important in the context of coping. A correction to existing studies is that firefighters do not always use black humor collectively when coping because of the possible differences in how some crew 
members perceive an incident as critical (whereas others do not); and this leads to different needs as regards coping with the incident. Another new insight is that there is no black humor at all with certain critical incidents. This mainly concerns incidents involving children and young adults where the firefighters felt helpless. In such situations, the use of humor would cross personal boundaries and break unwritten rules. Humor can help identify problems; if, after a critical incident, no jokes are made by the crew and/or if a crew member of the crew does not laugh about the jokes, it is usually a sign for the crew commander to pay extra attention to coping.

Social support is one of the most effective ways to help people cope with highstress situations (Kim et al. 2008): it reduces the negative psychological impact (Varvel et al. 2007) and stimulates resilience (Bernabé and Botia 2015). Firefighters use humor to ensure social support by developing group cohesion (Rowe and Regehr 2010). Given the importance of social support and especially the role of humor in coping with critical incidents, the strengthening of social cohesion and support among fire service crews should be promoted (see also Sattler et al. 2014). However, firefighters are reluctant to discuss the role of firefighters' humor or black humor. This closed attitude has led to a lack of understanding of this important coping strategy in the outside world. Providing information on the role of humor in the fire service culture in general, and specifically when coping with critical incidents, enables managers and mental health professionals to gain a better understanding of this unique work culture, and assistance and aftercare to be better attuned to the needs of firefighters.

\section{Strengths and limitations}

Only Dutch firefighters were involved in this study. So far, the extent to which the results can be generalized to firefighters from other countries is unclear.

The vast majority of Dutch firefighters are white, heterosexual men. Real life is reflected in that minorities such as women, gays and lesbians, and individuals with a migrant background are underrepresented in this study. This explains why it wasn't possible to pinpoint differences, if any, in how these groups use and perceive humor.

Lastly, this study involved both career and non-career firefighters. Besides similarities there may also be differences between how these two categories of firefighters experience critical incidents and their type and frequency; coping and opportunities for coping - with such incidents; and the fire service culture. A follow-up study will examine this topic in more detail. 


\section{References}

Bernabé, Miguel \& José Manuel Botia. 2015. Resilience as a mediator in emotional social support's relationship with occupational psychology health in firefighters. Journal of Health Psychology 21(8). 1778-1786.

Charman, Sarah. 2013. Sharing a laugh. The role of humour in relationships between police officers and ambulance staff. International Journal of Sociology and Social Policy 33(3/4). 152-166.

Dangermond, Karin, Ricardo Weewer, Joachim Duyndam \& Anja Machielse. 2021. "The problem hasn't changed, but you're no longer left to deal with it on your own." The role of informal peer support in helping firefighters cope with critical incidents. Manuscript submitted for publication.

Fine, Gary Alan \& Michaela De Soucey. 2005. Joking cultures: Humor theories as social regulation in group life. Humor: International Journal of Humor Research 18(1). 1-22.

Floyd, Alan \& Linet Arthur. 2012. Researching from within: External and internal ethical engagement. International Journal of Research \& Method in Education 35(2). 171-180.

Fraess-Phillips, Alex, Shannon Wagner \& R. Luke Harris. 2017. Firefighters and traumatic stress: A review. International Journal of Emergency Services 6(1). 67-80.

Goble, Elizabeth. 2020. The culture of coping in paramedics. Adelaide: Flinders University.

Greatbatch, David \& Timothy Clark. 2003. Displaying group cohesiveness: Humor and laughter in the public lectures of management gurus. Human Relations 56.1515-1544.

Green, Melanie. 2014. On the inside looking in: Methodological insights and challenges in conducting qualitative insider research. The Qualitative Report 19(29). 1-13.

Gross, Frederick Walter. 2009. A phenomenological study of experiences in coping with critical events by urban first responders in a metropolitan area. Chicago, Illinois: Loyola University Chicago.

Gulliver, Suzy B., Michelle L. Pennington, Victoria A. Torres, Laurie E. Steffen, Amruta Mardikar, Frank Leto, William Ostiguy, Rose T. Zimering \& Nathan A. Kimbrel. 2019. Behavioral health programs in fire service: Surveying access and preferences. Psychological Services 16(2). 340-345.

Halpern, Janice, Maria Gurevich, Brian Schwartz \& Paulette Brazeau. 2009. What makes an incident critical for ambulance workers? Emotional outcomes and implications for intervention. Work \& Stress 23. 173-189.

Haslam, Cheryl \& Krissie Mallon. 2003. A preliminary investigation of post-traumatic stress symptoms among firefighters. Work \& Stress 17(3). 277-285.

Haverkamp, Gerrit. 2005. Vuur als gemeenschappelijke vijand. Den Haag: Reed Business Information.

Henderson, Sarah N., Vincent B. Van Hasselt, Todd J. LeDuc \& Judy Couwels. 2016. Firefighter suicide: Understanding cultural challenges for mental health professionals. Professional Psychology: Research and Practice 47(3). 224-230.

Jeannette, James M. \& Alan Scoboria. 2008. Firefighters preferences regarding post-incident intervention. Work \& Stress 22(4). 314-326.

Johnson, Candice C., Luzimar Vega, Alicia L. Kohalmi, Jennifer C. Roth, Brittany R. Howell, and Vincent B. Van Hasselt. 2020. Enhancing mental health treatment for the firefighter population: Understanding fire culture, treatment barriers, practice implications, and research directions. Professional Psychology: Research and Practice 51(3). 304-311. 
Kim, Heejung, David K. Sherman \& Shelley E. Taylor. 2008. Culture and social support. American Psychologist 63(6). 518-526.

Kniffin, Kevin M., Brian Wansink, Carol M. Devine \& Jeffery Sobal. 2015. Eating together at the firehouse: How workplace commensality relates to the performance of firefighters. Human Performance 28(4). 281-306.

Kuipers, Giselinde. 2009. Humor styles and symbolic boundaries. Journal of Literary Theory 3(2). 219-240.

Moran, Larry \& Gene Roth. 2013. Humor in context: Fire service and joking culture. New Horizons in Adult Education \& Human Resource Development 25(3). 14-26.

Netherlands Institute for Safety. 2020. Brandweerkerndata 2019. Arnhem: IFV.

O'Neill, Olivia Amanda \& Nancy P. Rothbard. 2017. Is love all you need? The effects of emotional culture, suppression, and work-family conflict on firefighter risk-taking and health. Academy of Management Journal 60(1). 78-108.

Patton, Michael Quinn. 2015. Qualitative research \& evaluation methods, 4th edn. Thousand Oaks/London: Sage.

Perryman, Jane. 2011. The return of the native: The blurred boundaries of insider/outsider research in an English secondary school. International Journal of Qualitative Studies in Education 24(7). 857-874.

Rowe, Alison \& Cheryl Regehr. 2010. Whatever gets you through today: An examination of cynical humor among emergency service professionals. Journal of Loss and Trauma 15(5). 448-464.

Sattler, David N., Bill Boyd \& Julie Kirsch. 2014. Trauma-exposed firefighters: Relationships among posttraumatic growth, posttraumatic stress, resource availability, coping and critical incident stress debriefing experience. Stress and Health 30(5). 356-365.

Schein, Edgar H. 1984. Coming to a new awareness of organizational culture. Sloan Management Review 25(2). 3-16.

Sliter, Michael, Aron Kale \& Zhenyu Yuan. 2013. Is humor the best medicine? The buffering effect of coping humor on traumatic stressors in firefighters. Journal of Organizational Behavior 35. 257-272.

Stanley, Ian H., Joseph W. Boffa, Melanie A. Hom, Nathan A. Kimbrel \& Thomas E. Joiner. 2017. Differences in psychiatric symptoms and barriers to mental health care between volunteer and career firefighters. Psychiatry Research 247. 236-242.

Strick, Madelijn. 2021. Funny and meaningful: Media messages that are humorous and moving provide optimal consolation in corona times. Humor: International Journal of Humor Research 34(2). 155-176.

Tamrakar, Trina, John Langtry, Mark Shevlin, Tracey Reid \& Jamie Murphy. 2020. Profiling and predicting help-seeking behaviour among trauma-exposed UK firefighters. European Journal of Psychotraumatology 11. 1-12.

Thurnell-Read, Thomas \& Andrew Parker. 2008. Men, masculinities and firefighting: Occupational identity, shop-floor culture and organisational change. Emotion, Space and Society 1. 127-134.

Varvel, Shiloh Jordan, Yuhong He, Jennifer K. Shannon, David Tager, Rashanta A. Bledman, Adipat Chaichanasakul, Monique M. Mendoza, and Brent Mallinckrodt. 2007. Multidimensional, threshold effects of social support in firefighters: Is more support invariably better? Journal of Counseling Psychology 54(4). 458-465.

Vass, Greg. 2017. Getting inside the insider researcher: Does race-symmetry help or hinder research? International Journal of Research \& Method in Education 40(2). 137-153. 
Ward, James \& Diana Winstanley. 2006. Watching the watch: The UK fire service and its impact on sexual minorities in the workplace. Gender, Work and Organization 13(2). 193-219.

Willinger, Ulrike, Andreas Hergovich, Michaela Schmoeger, Matthias Deckert, Susanne Stoettner, Iris Bunda, Andrea Witting, Melanie Seidler, Reinhilde Moser, Stephanie Kacena, David Jaeckle, Benjamin Loader, Christian Mueller, Eduard Auff. 2017. Cognitive and emotional demands of black humor processing: The role of intelligence, aggressiveness and mood. Cognitive Processing 18. 159-167.

Yoder, Janice D. \& Patricia Aniakudo. 1996. When pranks become harassment: The case of African American women firefighters. Sex Roles 35(5-4). 253-270.

\section{Bionotes}

\section{Karin Dangermond}

Netherlands Institute for Public Safety, Arnhem, Netherlands

University of Humanistic Studies, Utrecht, Netherlands

karin.dangermond@nipv.nl

https://orcid.org/0000-0003-0973-8872

Karin Dangermond is researcher at Netherlands Institute for Public Safety and PhD student at the University of Humanistic Studies, the Netherlands. Her work focuses on the human side of the fire service. Important topics are leadership, organization and culture of the fire service, and recruitment and retainment of non-career firefighters. She is currently completing her doctoral research into the role of fire service culture in coping with critical incidents.

\section{Ricardo Weewer}

Netherlands Institute for Public Safety, Arnhem, Netherlands

Ricardo Weewer is professor of Fire Service Science at Netherlands Institute for Public Safety. He is especially interested in practical participative research which can be easily applied by the fire and rescue service. Main topics are fire and rescue practice, human factors in decision making under stress, and organization and culture of the fire service. Before he obtained his professorship, he was a fire officer in Amsterdam and became deputy chief fire officer (DCFO) in 2004.

\section{Joachim Duyndam}

University of Humanistic Studies, Utrecht, Netherlands

\section{J.Duyndam@UvH.nl}

Joachim Duyndam (PhD in Philosophy) is professor emeritus of Humanism and Philosophy at the University of Humanistic Studies in the Netherlands. He is thoroughly educated in European philosophy and its history, with an accent on phenomenology and hermeneutics. His research is focused on the significance of exemplars to moral agency. His published articles (in English) include titles such as 'Hermeneutical Mimesis', 'Humanism, Resilience, and the Hermeneutics of Exemplary Figures', 'Ideals Today between Wishful Thinking and Realism', and 'Empathy and the Potential Body of Imagination'. 


\section{Anja Machielse}

University of Humanistic Studies, Utrecht, Netherlands

\section{A.Machielse@UvH.nl}

Anja Machielse, PhD, is professor of Humanism and Social Resilience at the University of Humanistic Studies in the Netherlands. The focus in her work is on the social embeddedness of human beings and the significance of social relationships, both for personal life and for the wider community. The tension between individual autonomy and the demand of the social environment is central to this. Important themes in her work are social isolation and loneliness, social resilience, existential problems and meaning in life. 